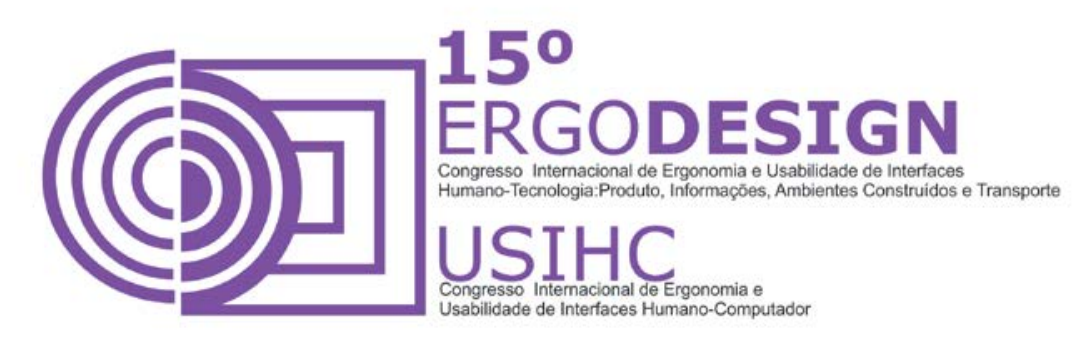

\title{
ANÁLISE ERGONÔMICA DO TRABALHO (AET): ESTUDO DE CASO NA GUARITA DA UEPA/PARAGOMINAS - CAMPUS VI
}

\section{ANALYSIS WORK ERGONOMIC (AET): A CASE STUDY IN THE GUARITA UEPA I PARAGOMINAS -CAMPUS VI}

\section{CAVAlCANTE, Rodrigo Augusto de Sousa (1); CARVALHO, Carlos Silva (2); SILVA, Daniela Lima da (3); OLIVEIRA, Maria Larissa de Moraes (4); NAZARÉ, Brena Renata Maciel (5)}

(1) Universidade do Estado do Pará, Graduando Bacharel em Design

e-mail:rodrigo_171192@hotmail.com

(2) Universidade do Estado do Pará, Graduando Bacharel em Design

e-mail: carlosjuniorcarvalho46@gmail.com

(3) Universidade do Estado do Pará, Graduando Bacharel em Design

e-mail: danielalima16@gmail.com

(4) Universidade do Estado do Pará, Graduando Bacharel em Design

e-mail: larissamoraes993@gmail.com

(5) Universidade do Estado do Pará, Especialista em Agente de Inovação e Difusão

Tecnológica

e-mail: brenarenata@yahoo.com.br

\section{RESUMO}

Através do método de analise ergonômica do trabalho, este projeto tem por objetivo analisar aos desvios ergonômicos presentes no local, a guarita instalada na UEPA de Paragominas - Campus VI e a importância da proposição de melhorias que contribuam para a promoção da segurança e bem-estar das pessoas. Por se tratar de um local na qual tem um grande fluxo de pessoas durante o funcionamento, 0 sistema homem-maquina-ambiente será observado por diferentes contextos.

Palavras-chave: Analise ergonômica, Ambiente de trabalho, Desconforto, Guarita.

\section{ABSTRACT}

By the method of Ergonomic work analysis, this project aims to analyze the ergonomic present deviations in place, the guardhouse installed in UEPA Paragominas - Campus VI and the importance of proposing 


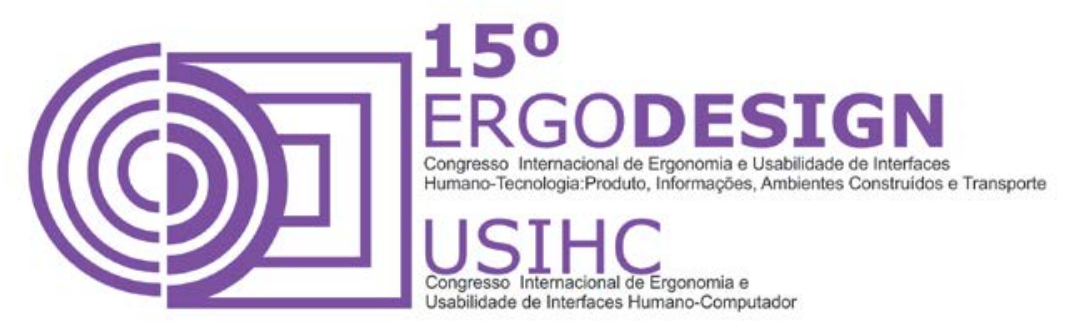

improvements that contribute to the promotion of security and well-being people. Because it is a place in which there is a large influx of people during the operation, the man-machine-environment system will be noticed by different contexts.

Keywords: Ergonomic Analysis, Working environment, discomfort, Guardhouse.

\section{INTRODUÇÃO}

A ergonomia tem a intenção de adaptar o ambiente e a máquina no qual ocorrem às interações durante a realização das atividades para que a consequência destas para o indivíduo sejam satisfatórias e não ultrapassem suas limitações físicas e cognitivas. No ambiente de trabalho, a ergonomia procura contribuir para o processo de aprimoramento às condições e à organização do trabalho. Soares (1999) justifica o propósito deste trabalho ao afirmar que a utilização de mobiliário e equipamentos com design adequado à realização das tarefas, aliados aos fatores ambientais como iluminação, ventilação, temperatura, ruído, organização espacial e higiene, são fundamentais para uma alta produtividade.

Especificamente no estudo de caso da guarita observa-se inicialmente que não existe sinergia na relação do sistema homem-maquina-ambiente, ou seja, os subsistemas não estão interagindo de maneira adequada e o resultado obtido não é favorável ao trabalhador. Na maioria das vezes, essas falhas são decorrências do fato de que a concepção de uma guarita nem sempre leva em consideração aspectos ergonômicos em sua configuração.

Deste modo, buscou-se fazer a analise ergonômica do trabalho no ambiente físico da guarita, localizada na cidade Paragominas região nordeste do estado Pará, a Universidade do Estado do Pará, Campus VI situada na rodovia PA-125, s/n. Levando em consideração o homem, a máquina e o ambiente. Com o objetivo de conhecer a opinião dos usuários com relação ao ambiente de trabalho, identificar as queixas de dores e os constrangimentos sentidos pelos funcionários decorrentes do uso do sistema inadequado, diagnosticar aspectos ergonômicos que interferem ou dificultam a realização das tarefas e propor melhorias (recomendações) no âmbito físico, cognitivo e organizacional.

\section{REFERENCIAL TEORICO}

Década de 1950 surgem os estudos sobre qualidade de vida no trabalho, principalmente no que se refere à satisfação do trabalhador com a organização e com a tarefa que executa. A necessidade da ergonomia é devido à complexidade das máquinas e a sua utilização, a sofisticação de aparelhos eletrônicos e computadores, o problema do ruído, da vibração, as condições térmicas do ambiente de trabalho, os trabalhos em série que têm levado o trabalhador rapidamente à fadiga, aos acidentes, ao baixo rendimento, às neuroses profissionais e às doenças psicossomáticas (DAVIS e NEWSTROM, 2004).

A Ergonomia, também denominada "Engenharia dos Fatores Humanos" busca a elaboração de projetos com a finalidade de diminuir ao máximo o esforço do funcionário no manuseio de seus 


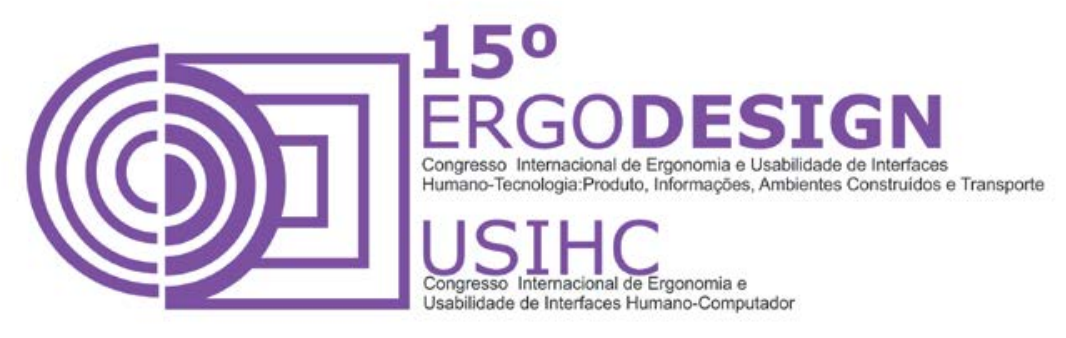

instrumentos de trabalho como máquinas, equipamentos, ferramentas, mobiliário dentre outros (ABERGO, 2009).

Segundo lida (2005), a ergonomia busca a segurança, satisfação e o bem-estar dos trabalhadores no seu relacionamento com sistemas produtivos. Sabendo-se que os sistemas produtivos evoluem com o desenvolvimento da tecnologia, à medida que as máquinas a cada dia assumem o trabalho pesado, aumentando a produtividade e a qualidade dos produtos, ao homem é designado o esforço mental e dos sentidos.

lida (2005) ainda enfatiza que uma unidade produtiva envolve um homem e o equipamento que ele utiliza para realizar o trabalho, bem como o ambiente que o circunda, dessa forma é a configuração física do posto de trabalho.

Uma guarita trata-se de um posto de trabalho que tem por finalidade prezar pela integridade física de pessoas e patrimônio de um determinado sistema produtivo (empresas, universidades, residências etc.). A guarita instalada na UEPA em Paragominas é importante para a segurança do campus, dessa forma é fundamental ter um espaço adequado que ofereça condições que contribuam para eficiência, desempenho das funções, e conforto dos vigilantes para longas jornadas de trabalho, a fim de evitar possíveis invasões indesejadas que possam pôr em risco a segurança das pessoas que frequentam diariamente o local, assim como possíveis danos à estrutura da universidade ou furto de bens e equipamentos. O posto em questão deve promover um equilíbrio entre as necessidades do trabalhador e as da Universidade objetivando que as tarefas possam ser desempenhadas de forma satisfatória para ambos.

Devido a todas essas necessidades foram criadas as Normas Regulamentadoras (NR), da consolidação das leis do trabalho, relativas à segurança e medicina do trabalho, aprovada em 08 de Junho de 1978, Portaria n.3.214. São 28 normas regulamentadoras de segurança e saúde do trabalhador, que buscam proteger e prevenir os trabalhadores de possíveis doenças ocupacionais, dentre elas a NR17 - ergonomia, que visa estabelecer parâmetros que permitam à adaptação das condições de trabalho as características psicofisiológicas dos trabalhadores, de modo a proporcionar um máximo de conforto, segurança e desempenho eficiente.

A partir desses conceitos, foram feitas observações e coletas de informações necessárias para detectar as várias irregularidades estruturais e organizacionais existentes no posto de vigilância que interferem diretamente na segurança do campus e na qualidade das atividades dos vigilantes. Uma nova organização desse espaço trará melhorias significativas para os vigilantes, que aumentarão o desempenho dos mesmos e a segurança da instituição de ensino.

\section{MATERIAIS E MÉTODOS}

O método científico norteador desta pesquisa é o proposto por lida (2008), denominado Análise Ergonômica do Trabalho (AET) que se divide em analise da demanda, tarefa, atividade, diagnóstica e recomendações ergonômicas.

Para o desenvolvimento da analise da demanda realizou-se a pesquisa bibliográfica e documental, através de levantamento de dados em diferentes fontes de informação, visando 


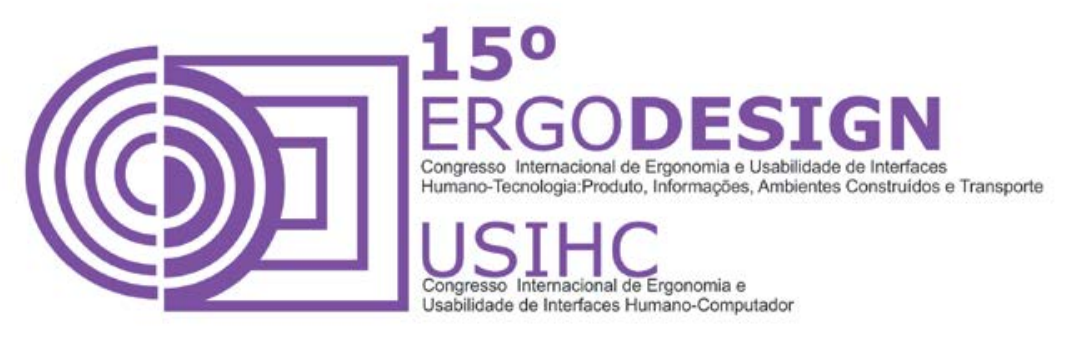

obter conceitos teóricos e história do objeto de estudo, diante desta etapa foi selecionado como referencia de método a norma NR17.

Para á analise da tarefa e atividade desenvolveu-se a pesquisa exploratória, através de visitas técnicas ao posto de trabalho, aplicação de questionário semiestruturado com os funcionários em dois turnos e registro imagético dos trabalhadores durante a realização de suas atividades por meio de observação direta. Para diagnóstico e recomendações ergonômicas foram utilizadas variáveis quantitativas e qualitativas.

\section{RESUTADOS E DISCUSSÕES.}

\subsection{Analise da Demanda}

A guarita é um local de vigilância onde é feito o monitoramento de segurança durante a entrada e saída de pessoas em um ambiente com trafego constante. $\mathrm{Na}$ qual possui $9.86 \mathrm{~m}^{2}$ e localizada na Universidade do Estado do Pará, UEPA - Campus VI, Paragominas. O espaço apresenta-se precário com diversos problemas organizacionais e estruturais, com dimensões inadequadas para cumprir sua função de maneira eficiente.

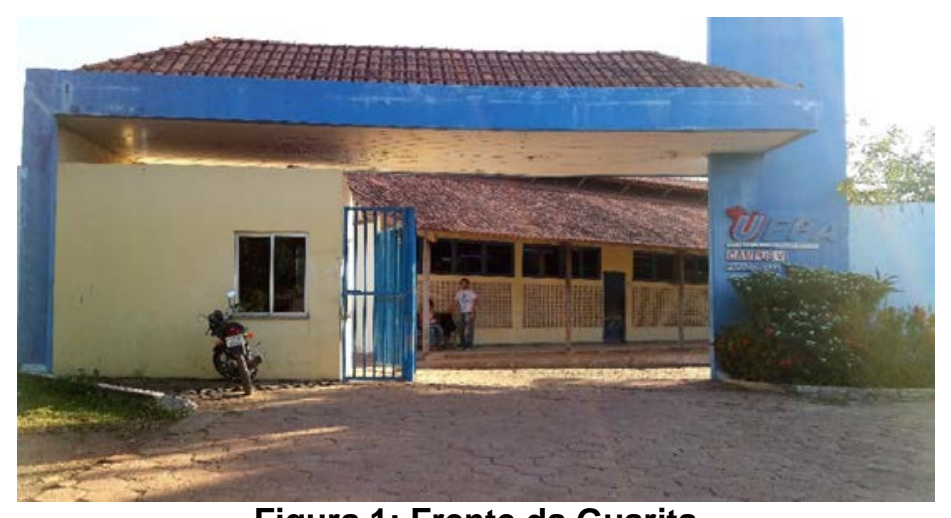

Figura 1: Frente da Guarita

Fonte: Acervo Pessoal

De acordo com lida (2005. p. 60), a analise da demanda é a descrição de um problema ou uma situação problemática, que justifique a necessidade de uma ação ergonômica. A guarita do campus encontra-se exposta diretamente ao sol durante a tarde. Esse horário torna-se impossível à permanência no local devido ao calor excessivo e para minimizar esse problema os vigilantes contam apenas com um aparelho de ventilador. 

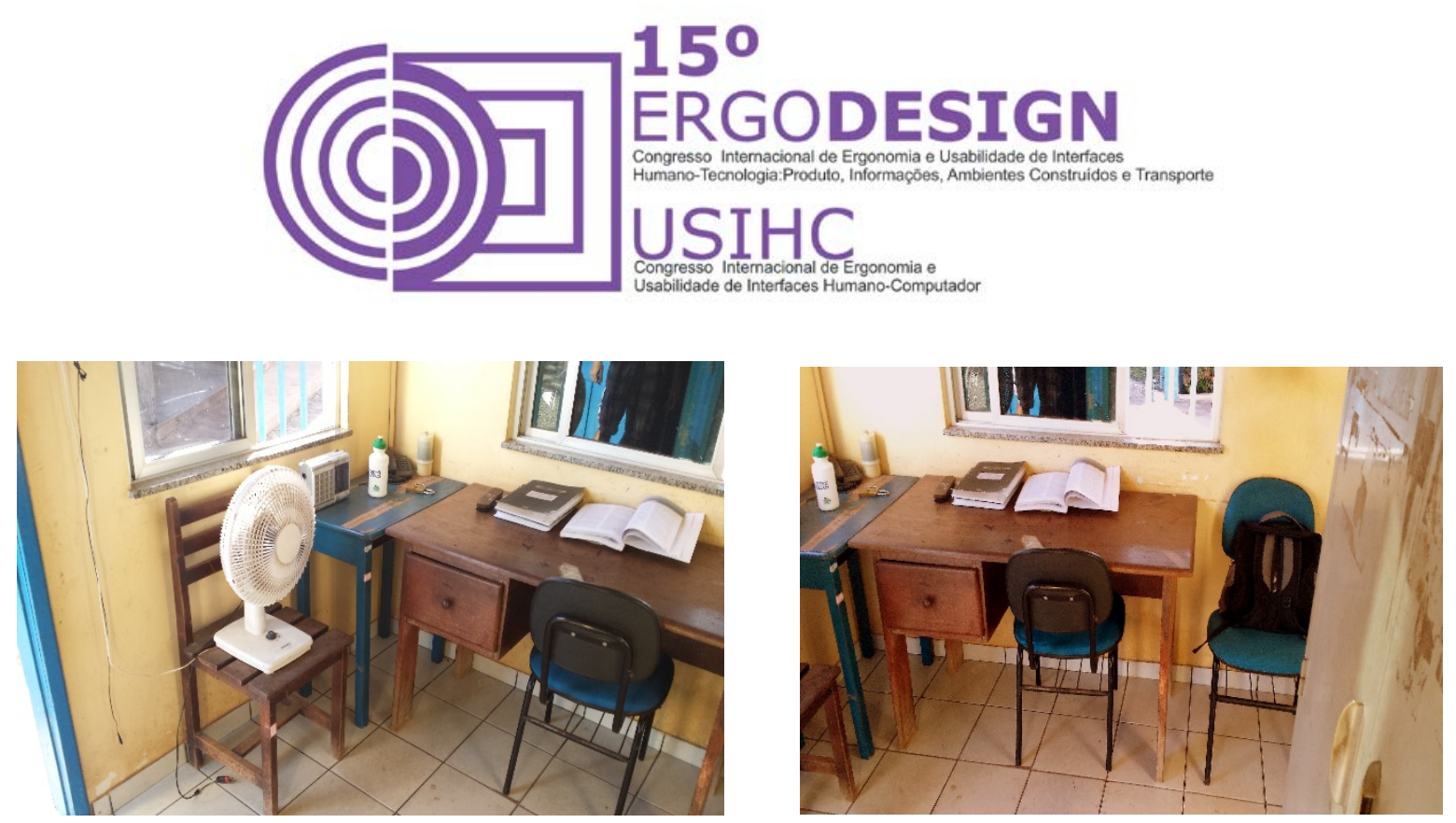

Figura 2 e 3: Interior da Guarita

Fonte: Acervo Pessoal

O banheiro da guarita é totalmente desproporcional às medidas antropométricas dos usuários, fora dos parâmetros ergonômicos, sua área é minúscula, ou seja, mal planejada. A porta do banheiro ao ser aberta atrapalha o uso da pia (figura 4 e 5), a lâmpada não possui acabamento isolante e quase não existe espaço entre o vaso sanitário e a parede, impedindo a passagem do usuário, além de dar uma sensação de sufocamento a quem está dentro.
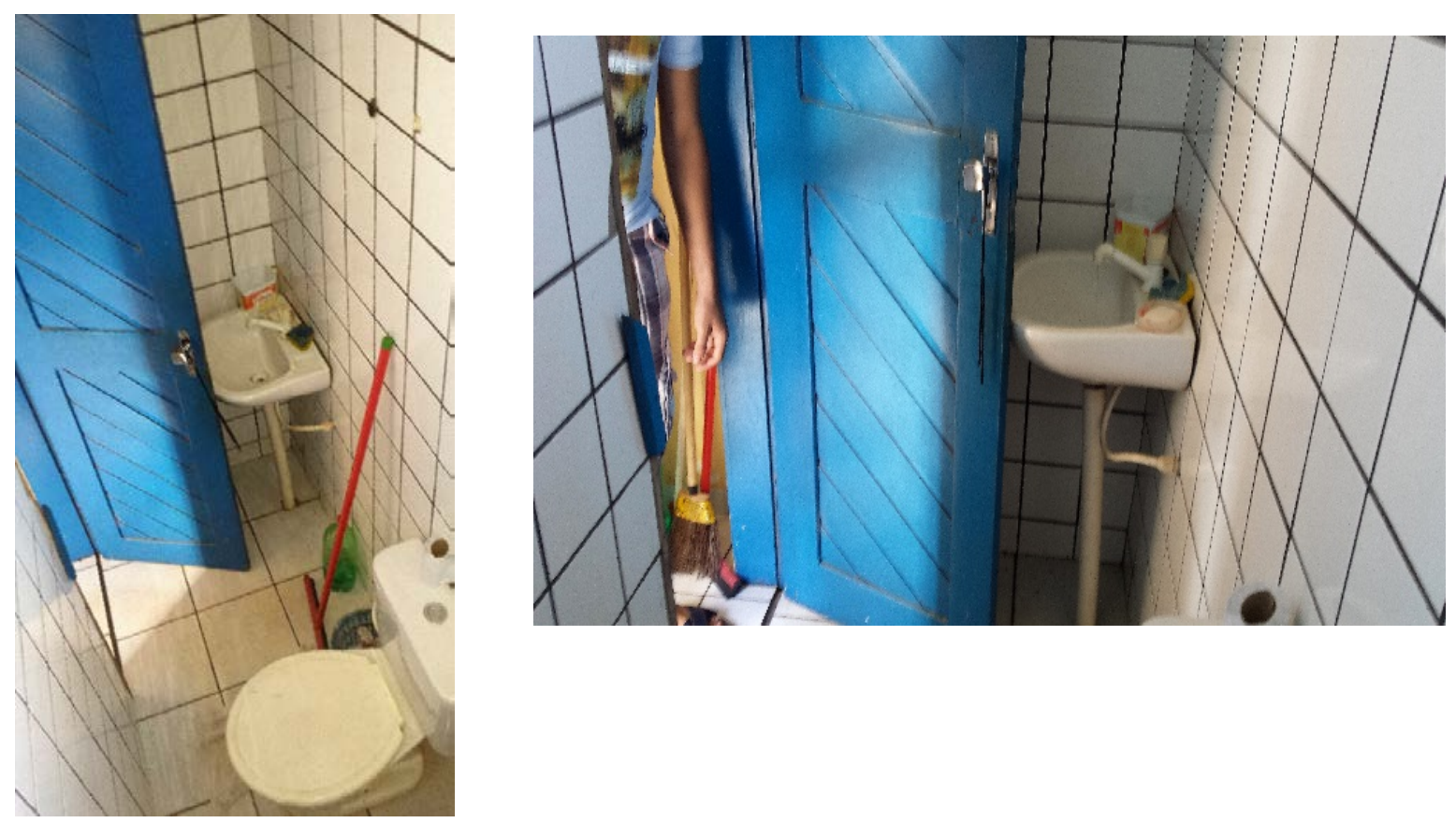

Figura 4 e 5: Interior do Banheiro Fonte: Acervo Pessoal 


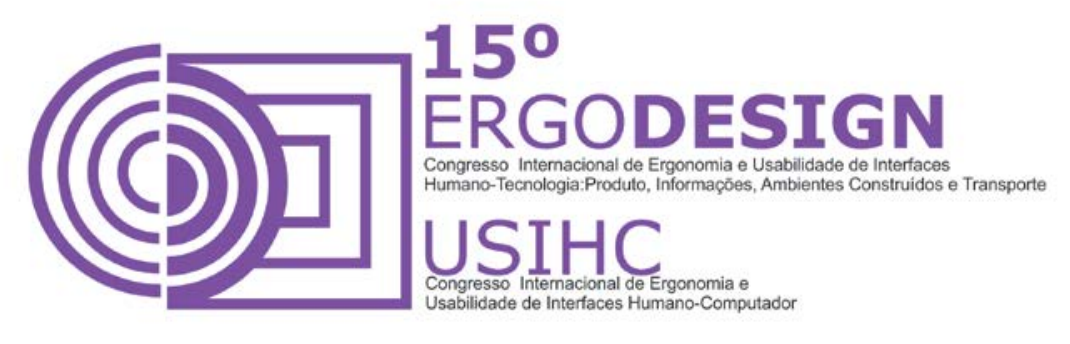

Os móveis são improvisados, usados, desgastados e estão mal posicionados, provocando desconforto e interferindo na mobilidade e ações de manejo. A cadeira do vigilante é fixa e pouco confortável, inadequada para um posto de trabalho em que é preciso passar longos períodos sentados, já que se trata de uma carga horária de 12 horas diárias.

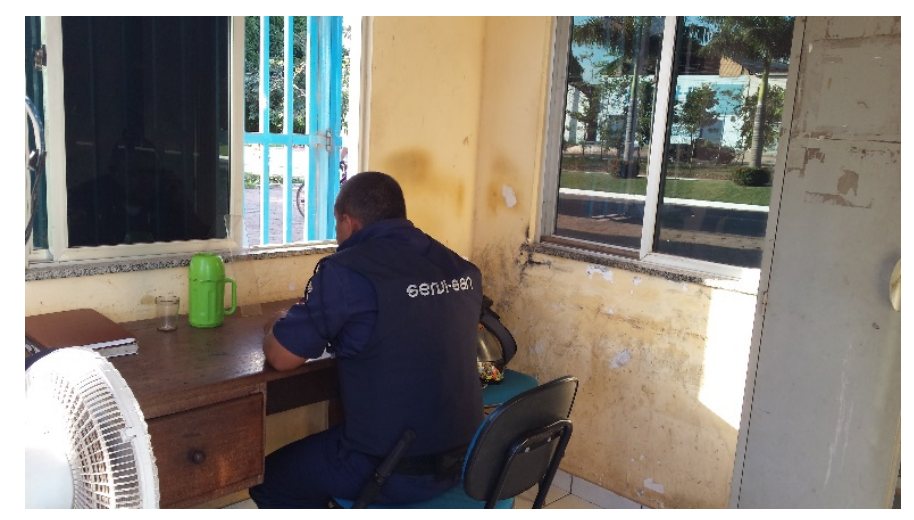

Figura 6: Vigilante Sentando

Fonte: Acervo Pessoal

O local não apresenta equipamentos tecnológicos suficientes para auxiliar no trabalho dos vigilantes e para garantir a eficácia do serviço. O portão principal é totalmente manual, e fica aberto por quase todo o dia, o que facilita o acesso das pessoas, porém dificulta o controle necessário para impedir a entrada de pessoas estranhas que podem comprometer a segurança do campus.

\subsection{Analise da Tarefa}

A tarefa é um conjunto de objetivos prescritos, que os trabalhadores devem cumprir. Ela corresponde a um planejamento do trabalho e pode estar contida em documentos formais, como a descrição de cargos. Informalmente, pode corresponder a certas expectativas gerenciais. (IIDA, 2005, p. 60).

No caso dos vigilantes, eles são contratados por uma empresa terceirizada SERVI-SAN Vigilância e Transportes de Valores Ltda. Sua jornada de trabalho é de 12 horas, com intervalo de 36 horas de descanso para cada vigilante. A guarita possui 4 vigilantes que revezam entre si, dois vigilantes diurno com início às $7 \mathrm{~h}$ e encerramento às $19 \mathrm{~h}$, e dois noturnos com início às $19 \mathrm{~h}$ até às 7 horas da manhã. Suas atividades para a manutenção da segurança são:

- Controle de acessos (pedestres mercadorias e veículos); 


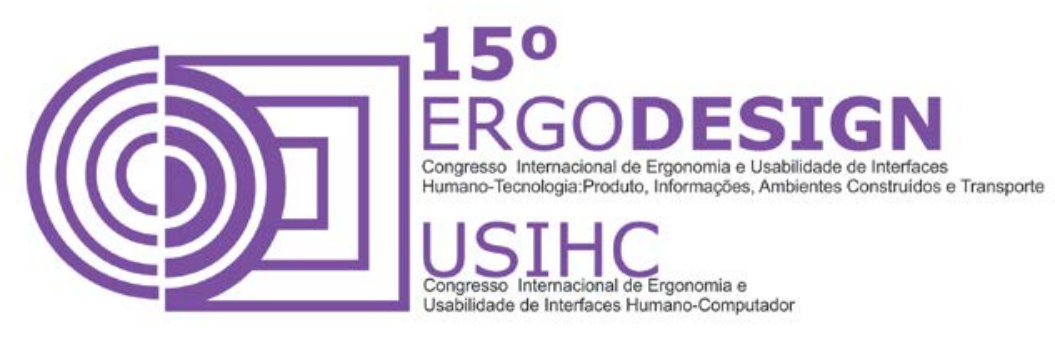

- Prevenção de furtos e roubos;

- Vigilância ostensiva.

\subsection{Analise da Atividade}

Tem o proposito de analisar o comportamento do trabalhador, na realização de uma tarefa. É a maneira como o trabalhador procede para alcançar os objetivos que lhe foram atribuídos (IIDA, 2005 , p. 60). Ela resulta de um processo no qual o individuo durante a interação com a máquina e o ambiente, promove certas adaptações de acordo com as variáveis apresentadas durante a realização do trabalho.

Ao chegarem ao seu local de trabalho, os vigilantes fazem uma ronda por todo o local para garantir se patrimônio material do campus se apresenta dentro das conformidades após o término do turno do anterior. A ronda é feita em vários momentos durante os turnos pelo próprio vigilante, mas a frequência aumenta no período noturno, pois não há fluxo de pessoas transitando no local o que torna vulnerável a entrada de pessoas que possam oferecer algum risco ao patrimônio da instituição. Os vigilantes são responsáveis também por ligar e desligar lâmpadas e ar condicionados e abrir e fechar as portas das salas de dentro do campus.

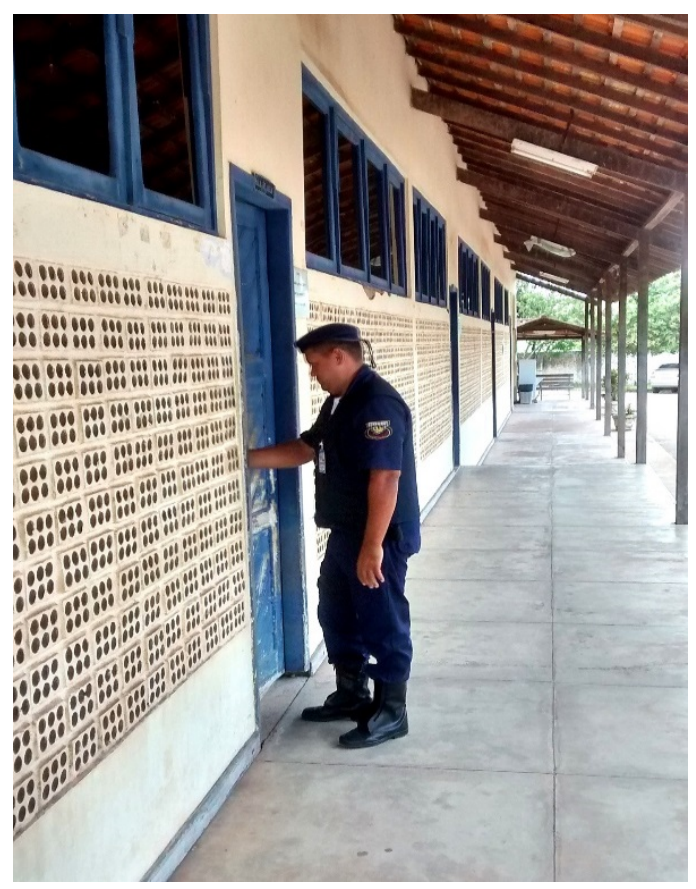

Figura 7: Vigilante Verificando as Salas Fonte: Acervo Pessoal 


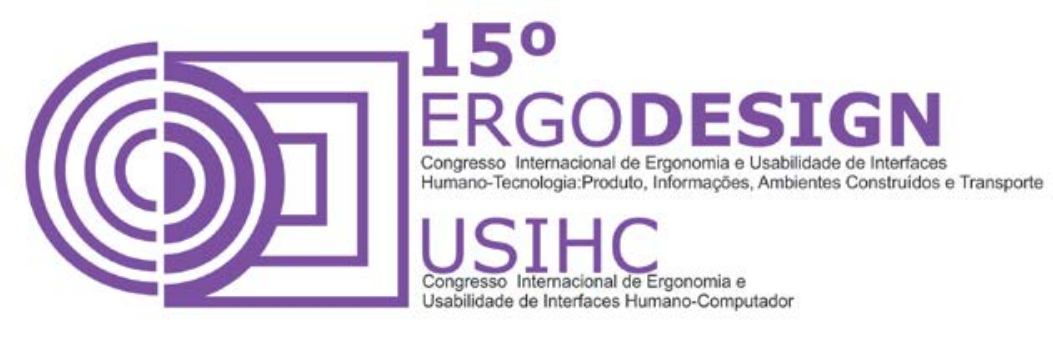

Houve determinada situação em que uma pessoa estava sentada no muro do campus, e para impedir que esse indivíduo entrasse no local o vigilante, com receio de sair de seu posto de trabalho para impedir a ação e haver outra invasão pela entrada, teve que pedir ajuda para seu colega de trabalho que estava de folga visando verificar o que estava acontecendo aos fundos, porém se algo de ruim acontecesse com ele à empresa não se responsabilizaria.

Os vigilantes passam grande parte do tempo sentado na guarita e precisam estar sempre atentos a qualquer irregularidade. No turno do tarde eles reclamam do calor excessivo dentro do local, que tem exposição direta ao sol, sendo obrigados a ficar do lado de fora próximo ao portão de entrada.
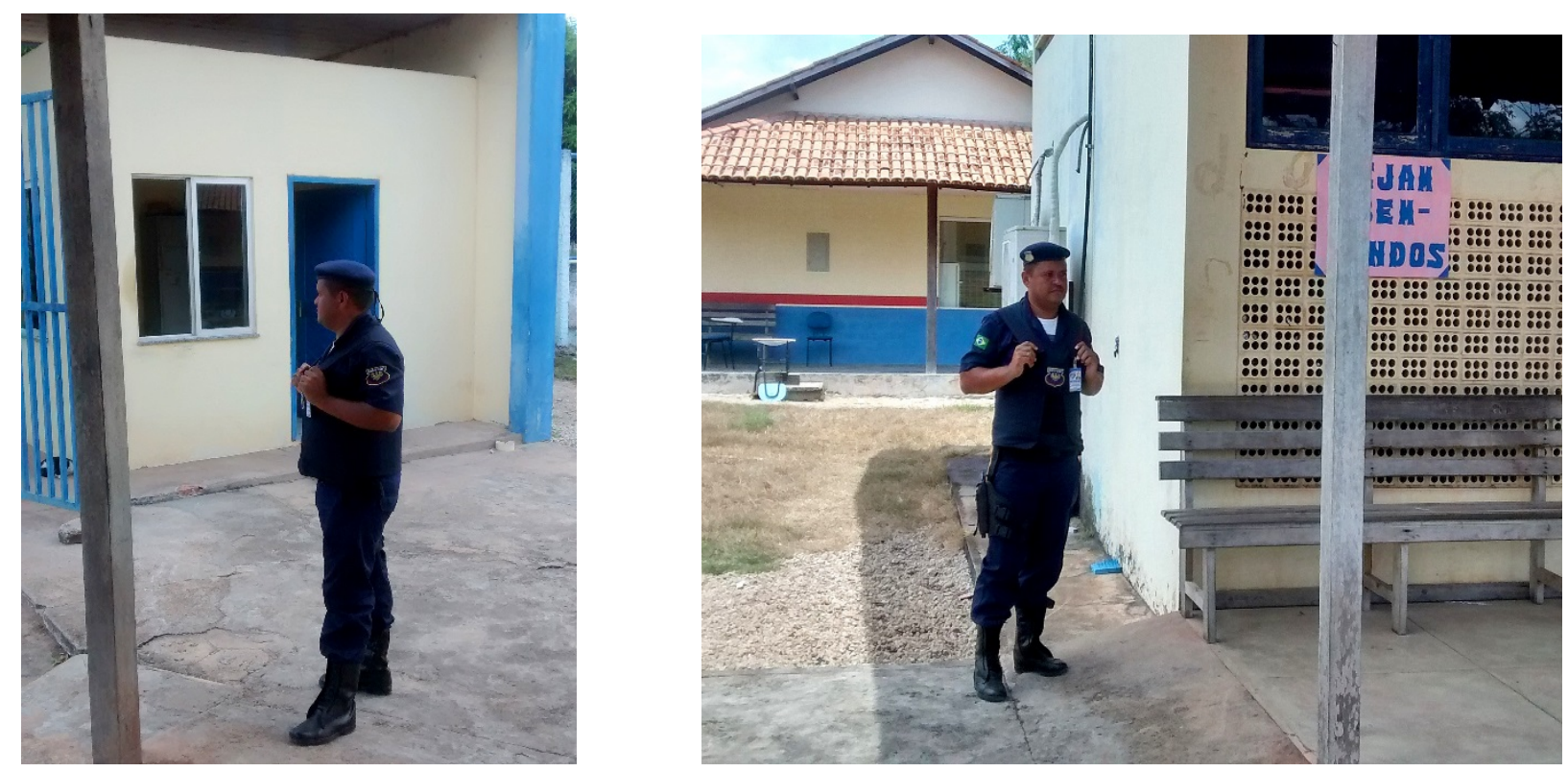

Figura 8 e 9: Vigilante Fora da Guarita

Fonte: Acervo Pessoal

Para manter seu profissionalismo, os mesmos não mantem diálogos paralelos, somente saudações e informações da coordenação do campus no fim da semana. Eles não têm reclamações em relação às pessoas que frequentam diariamente o ambiente.

A empresa fornece vales de alimentação, mas por não poderem se ausentar do posto de trabalho por muito tempo, contam com uma pessoa para levar a comida até a instituição. Todas as refeições são feitas dentro do posto de trabalho por no máximo meia hora. Eles trazem café e água em garrafas térmicas para não se afastar do local.

No caso de precisarem utilizar o banheiro dentro da guarita, se ausentam deixando a entrada desprotegida por alguns minutos. Se precisarem sair por algum problema de saúde, pessoal ou 


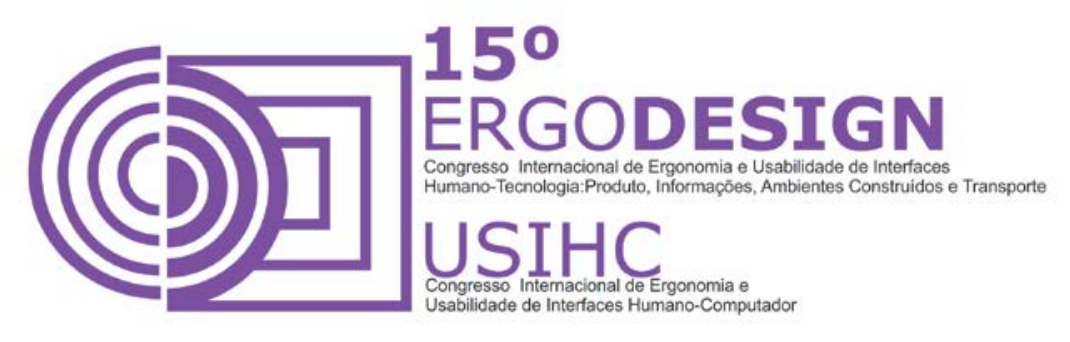

familiar o vigilante tem que solicitar sua substituição onde o mesmo só será liberado após outro tomar seu posto.

\subsection{Diagnostico}

A partir da análise ergonômica feita na guarita do campus VI, detectaram-se várias não conformidades que interferem nas condições e funções do trabalho dos vigilantes, segundo a norma NR 17 que ampara a ergonomia, o parágrafo 17.1 é importante visar e estabelecer parâmetros que permitam a adaptação das condições de trabalho às características psicofisiológicas dos trabalhadores, de modo a proporcionar um máximo de conforto, segurança, desempenho e eficiência.

A excessiva sobrecarga visual pode disparar queixas geralmente atribuídas à fadiga visual, consequência da exclusiva e intensiva exigência da musculatura de acomodação, o músculo ciliar (Grandjean, 1998). Devido à carga horaria de 12 horas seguidas sem intervalos e por ser somente um vigilante por turno para garantir a segurança de todo o campus sem ajuda, ocasiona fadiga excessiva e monotonia ao trabalhador e no período noturno o desconforto aumenta a probabilidade de sonolência.

A NR-17, estabelece que a temperatura em ambientes de trabalho deve estar entre $20^{\circ} \mathrm{C}$ e $23^{\circ} \mathrm{C}$. No período diurno o calor é frequente, ultrapassando o estabelecido pela norma. Por se localizar em uma área de maior exposição ao sol e se torna impossível à permanência por muito tempo dentro da mesma, ocasionando fadiga e estresse levando assim o vigilante passar a maior parte do tempo de seu turno em pé ao lado de fora.

O local também é composto por um mobiliário desgastado, a cadeira utilizada é inadequada ergonomicamente, causando incômodo e provocando dores no corpo de quem está sentado por um longo período. Portanto, não atendem a norma NR 17 do parágrafo 17.3.3. A onde afirma que os assentos utilizados nos postos de trabalho devem atender aos seguintes requisitos mínimos de conforto:

a) altura ajustável à estatura do trabalhador e à natureza da função exercida;

b) características de pouca ou nenhuma conformação na base do assento;

c) borda frontal arredondada;

d) encosto com forma levemente adaptada ao corpo para proteção da região lombar.

Couto (1995) pontua algumas regras de ergonomia para a posição sentada. Para a ergonomia da cadeira de trabalho:

- A cadeira de trabalho deve ser estofada, e de preferência, com tecido que permita a transpiração;

- A altura da cadeira deve ser regulável;

- A dimensão anteroposterior do assento não pode ser nem muito comprida nem muito curta; 


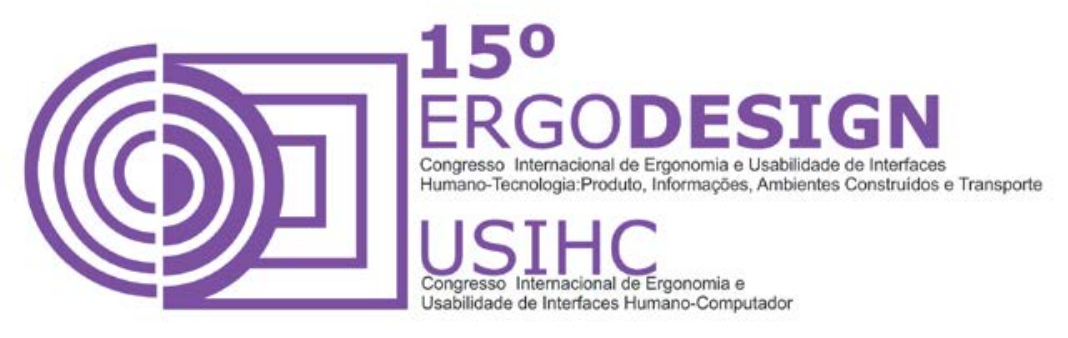

- A borda anterior do assento deve ser arredondada;

- O assento deve estar na posição horizontal; são desejável que o assento se incline 10 a 15 graus para frente. Assentos inclinados para trás são inadequados em cadeiras de trabalho;

- Toda cadeira de trabalho deve ter apoio para o dorso;

Nos momentos de repouso dos vigilantes na cadeira compatível às suas necessidades é extremamente essencial para os instantes de descanso, diferente da cadeira de uso escolar que foi doada pelo campus, com estofado desgastado, ocasionando dores nas costas, no pescoço e lombares. A cadeira não possui uma rotação para diversos ângulos, o vigilante tem que se levantar e se locomover até as janelas para ter uma visão ampla, ou rotacionar o tronco levando-o a ficar em uma postura incorreta.

A mesa usada para escrita e refeições, está dentro dos padrões ergonômicos, com áreas de manejo que não comprometem às ações. O desgaste interfere somente na aparência. $O$ banheiro dentro da guarita é mal planejado, pequeno, tornando difícil a locomoção em seu interior, a porta quando se abre bate na pia, o espaço de passagem entre o vaso e parede é pequeno, uma pessoa de porte médio não transita com facilidade.

A janela da guarita que dá visão para fora do campus, não tem proteção especial, por ser de vidro tem um grande perigo de invasão, para não serem forçados por algum indivíduo que queiram adentrar, os guardas contam com total improviso, um cabo de vassoura usado para conter forçamento se houver alguma tentativa invasão.

O telefone está disponível somente para ligações em ramal, impossibilitando ligações externas em caso de necessidade de se comunicar com a empresa que os contratam assim como em caso de alguma solicitação de auxilio externo. Como por exemplo: caso ocorra um incêndio ou acidente dentro do campus no período de não funcionamento da secretaria que possui telefone para ligações externas.

Por ficar apenas um vigilante por turno de trabalho, o excesso de tarefas exigidas, a ausência de pausas regulares bem como a sobrecarga mental pode levar o funcionário ao estresse físico e mental.

\subsection{Recomendações Ergonômicas}

Baseando-se no diagnostico as condições dos postos de trabalho e, no desconforto sentido pelos trabalhadores, tornam-se necessárias algumas mudanças no ambiente, para minimizar as inadequações do posto de trabalho, estabelecendo parâmetros e diretrizes mínimas para adequações das condições de trabalho visando à prevenção dos problemas de saúde futuramente relacionadas ao trabalho, propõem-se as seguintes soluções:

- Ar condicionado para a melhor climatização do local e controle de temperatura.

- Cadeira adequada, ergonomicamente correta, rotatória, apoio de braço, regulagem de altura e encosto, e com rodinha para movimentação do corpo em repouso.

- Mesa de aparência inovada, ou reforma da mesa atual. 


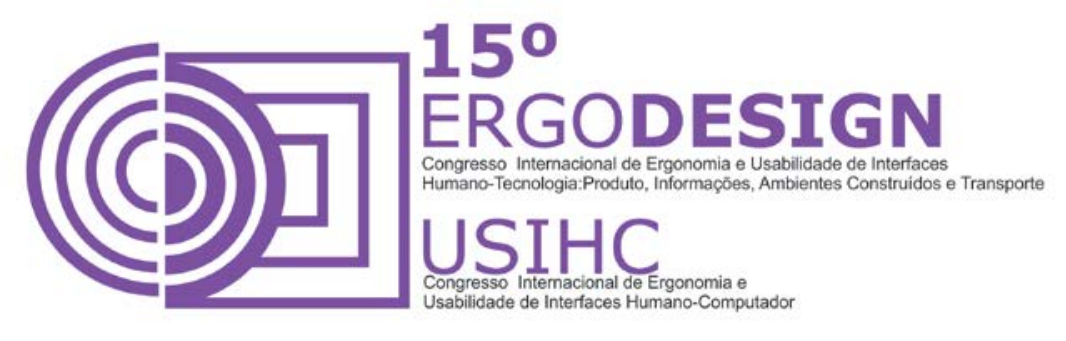

- Banheiro, planejamento organizacional levando em consideração as medidas antropométricas dos usuários, bem com espaços de movimentação e dimensionamento de folgas.

- Telefone que faça chamada externas ao campus.

- Bebedouro no interior da guarita para ameniza o calor e evitar a saída do posto de trabalho.

- Câmeras em pontos estratégico do campus para aumentar a segurança.

- Aumento no quadro de funcionários por turno. O ideal que sejam dois vigilantes, um especifico para a portaria e outro responsável pela ronda na área do campus.

A NR 17 cita como principal objetivo estabelecer parâmetros que permitam à adaptação das condições de trabalho as características psicofisiológicas dos trabalhadores, de modo a proporcionar um máximo de conforto, segurança e desempenho eficiente. Isso denota a necessidade de melhorias para contribuir com a Qualidade de Vida no Trabalho e alavancar a produtividade e desempenho entre homem-maquina-ambiente.

Analisando-se com atenção, é certo que não se pode desconsiderar a importância de pesquisas com os usuários diretos, as quais permitem determinar critérios projetuais integralizados que contribuem expressivamente para a operacionalização da analise entre o homem-maquinaambiente, justamente no momento de aprimoramento e validação das soluções focadas na usabilidade, garantindo esse princípio já nas fases iniciais do estudo. Entretanto, o desenvolvimento de procedimentos metodológicos de avaliação e análise do trabalho também contribui de forma expressiva à aplicação do design ergonômico, uma vez que, é através desses procedimentos que se cria a oportunidade de avaliar de modo satisfatório a usabilidade para propor melhores condições de trabalho.

\section{CONCLUSÃO}

Após finalizar a análise das condições de trabalho da guarita compreende-se que cada cargo exige adequações diferentes para execução de suas funções, podem-se propor mudanças dentro de um estudo ergonômico que adaptassem a estrutura e organização do local às suas tarefas a fim de promover melhoria, a falta delas causa uma série de danos à saúde, bem estar, rendimento e qualidade das funções desempenhadas. Portanto, a aplicação da ergonomia é fundamental para promover essas adaptações específicas que cada posto de trabalho exige. As condições de trabalho ao quais ao vigilante são submetidos interferem diretamente no desenvolvimento das funções e consequentemente no nível de segurança do local, e em outros fatores físicos e psicológicos.

\section{REFERÊNCIAS BIBLIOGRÁFICAS}

ABERGO- Associação Brasileira de Ergonomia. Disponível em: http://www.abergo.org.br/oqueeergonomia.htm. Acesso: 16 de jan. de 2015. 


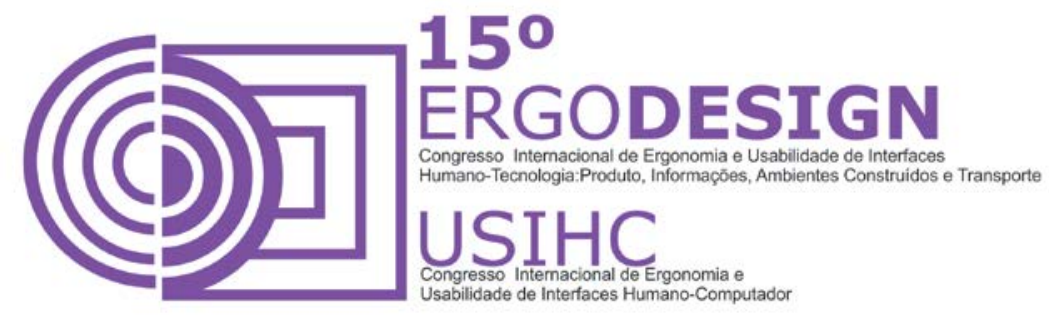

COUTO, H. de A. Ergonomia aplicada ao trabalho: o Manual técnico de máquina humana. Vol 1. Belo Horizonte: Ergo Editora, 1995.

DAVIS, K; NEWSTROM, J. W. Comportamento humano no trabalho: uma abordagem organizacional. São Paulo: Pioneira Thomson Learning, 2004. Volume 2.

DUL, Jan. WEERDMEESTER, Bernard. Ergonomia Prática. Tradutor Itiro Lida.- $2^{a}$ edição ver. E ampl. - São Paulo: Edgard Blücher, 2004. Cap. 6

GUEDES, Helena. Metodologia científica; Questionário. Campina Grande: UFPB/ CCT/DDI, 2000. (Apostila - Curso de Graduação em Desenho Industrial).

GRANDJEAN, E. Manual de Ergonomia: adaptando o trabalho ao homem. 4 ed. Porto Alegre: Bookman, 1998.

LIDA. Itiro. Ergonomia: Projeto e Produção. $2^{a}$ edição ver. E ampl. - São Paulo: Edgard Blücher, 2005. Cap. 2.

Ministério do Trabalho e Emprego. Manual de aplicação da norma regulamentadora $\mathbf{n}^{\circ} 17$. 2.ed. Brasília: MTE/SIR, 2002.

Segurança Patrimonial. Disponível em: <http://www.servi-san.com.br/>. Acessado em: 14 ago. 2014

SOARES, F. C. Otimização do ensino de informática através da aplicação dos conceitos de ergonomia no ambiente físico. Um estudo de caso: curso técnico de informática do CEFET/SC. 1999. Dissertação (Mestrado em Engenharia de Produção) - Universidade Federal de Santa Catarina, Florianópolis, SC. 